\title{
Hemophagocytic lymphohistiocytosis and miliary tuberculosis in a previously healthy individual: a case report
}

\author{
Linn Hereide Trovik', Miriam Sandnes², Bjørn Blomberg ${ }^{1,2}$, Gunhild Holmaas ${ }^{3}$, Aymen Bushra Ahmed', \\ Tor Henrik Anderson Tvedt ${ }^{1}$, Olav Vintermyr ${ }^{4,5}$ and Håkon Reikvam ${ }^{1,2^{*}}$ (B)
}

\begin{abstract}
Background: Hemophagocytic lymphohistiocytosis $(\mathrm{HLH})$ is a rare heterogenous genetic or acquired hyperinflammatory syndrome associated with a high degree of morbidity and mortality. HLH has clinical manifestations related to abnormal prolonged activation of T lymphocytes and macrophages with an excess of proinflammatory cytokines. The main causes of secondary HLH are malignancies and infectious diseases.

Case presentation: The patient was a 54-year-old man, originally from Eastern Africa, who had lived in Northern Europe for 30 years. Here we describe the clinical features, laboratory parameters, diagnostic workup, management and outcome data of a previously healthy 54-year-old man diagnosed with HLH secondary to tuberculosis. The patient was initially treated for a community-acquired pneumonia. He developed multiorgan failure with acute respiratory distress syndrome, hypertransaminasemia, and kidney and bone marrow dysfunction. The clinical course together with a simultaneous increase in serum ferritin raised the suspicion of $\mathrm{HLH}$. The patient fulfilled seven out of eight diagnostic criteria for HLH. A thorough diagnostic workup with respect to HLH and a potential underlying disease was initiated. Cultivation of bronchoalveolar lavage fluid, stool and urine, and polymerase chain reaction of epithelioid cell granulomas in the bone marrow were all positive for Mycobacterium tuberculosis. He was treated for both HLH and tuberculosis, and he survived without any sequelae.
\end{abstract}

Conclusions: We present one of few published cases of a patient who survived HLH triggered by miliary tuberculosis. The current case illustrates the need for awareness of these two diagnoses, and the timely initiation of specific and supportive treatment to reduce mortality.

Keywords: Cytokines, Ferritin, Hemophagocytic lymphohistiocytosis, Infection tuberculosis

\section{Introduction}

Hemophagocytic lymphohistiocytosis (HLH) is an uncommon hematologic disorder characterized by an uncontrolled immune response with organ infiltration of lymphocytes and histiocytes, and organ damage caused by excessive production of pro-inflammatory cytokines

*Correspondence: Hakon.Reikvam@med.uib.no

2 Department of Clinical Science, Institute of Clinical Science, University of Bergen, Bergen, Norway

Full list of author information is available at the end of the article
[1-6]. HLH is categorized either as primary due to a genetic disorder, or as secondary due to an acquired condition. Secondary HLH can be triggered by neoplastic and non-neoplastic diseases [7]. Malignancies associated with secondary HLH are mainly various hematological malignancies such as leukemia or lymphoma, whereas autoimmune disorders and infectious diseases are the most common nonmalignant diseases associated with HLH [3, 8]. While active tuberculosis (TB) is rare in the Nordic countries, the World Health Organization estimates 10 million new TB cases globally causing 1.5 
million deaths every year, thus making Mycobacterium tuberculosis the single most lethal infectious agent in the world $[9,10]$. HLH due to TB is very uncommon, with only a few cases reported, mostly in immunocompromised patients $[8,11-13]$.

Here we report a case of HLH associated with miliary TB in an apparently immunocompetent healthy man. The case illustrates that the combination of an aggressive diagnostic approach, searching for a broad variety of disorders, combined with an early therapeutic intervention are crucial to securing a successful outcome.

\section{Case presentation}

The patient was a 54-year-old man, originally from Eastern Africa, who had lived in Northern Europe for 30 years. Apart from increased blood pressure, causing mild left ventricle hypertrophy, he was healthy and only taking antihypertensive medication. He contacted his family physician due to nausea and loose, yellowish stools. Due to dysuria and microhematuria, he had received treatment with orally administered mecillinam for a suspected urinary tract infection. As this treatment had no effect, he was given doxycycline on suspicion of respiratory tract infection due to dyspnea and fever. Eventually, he was admitted to the hospital after 10 days of nausea, anorexia, diarrhea, frequent micturition, dyspnea, persistent fever, increasing C-reactive protein (CRP) and elevated liver transaminases. He had no cough, night sweats or weight loss. On clinical examination on admission, he was alert and oriented, but hypotensive (blood pressure 102/58 $\mathrm{mmHg}$ ) and hypoxic with $\mathrm{SpO}_{2}$ of $86 \%$ without supplemental oxygen. The responsible clinician described mild scleral jaundice, but no rashes or palpable adenopathy. Pulmonary auscultation revealed bilateral crackles. Laboratory test values showed hemoglobin level of $15.4 \mathrm{~g} / \mathrm{dL}$ (reference 13.4-17.0), leukocyte count at $10.410^{9} / \mathrm{L}$ (ref 3.5-11.0) and thrombocytes at $22010^{9} / \mathrm{L}$ (ref 145-348). CRP was elevated at $118 \mathrm{mg} / \mathrm{L}(\mathrm{ref}<5)$. Erythrocyte sedimentation rate was not taken at admission. He had acute kidney failure with creatinine at $297 \mu \mathrm{mol} / \mathrm{L}$ (ref 60-105), and elevated liver transaminases with alanine aminotransferase of $208 \mathrm{U} / \mathrm{L}$ (ref 10-70), alkaline phosphatase $191 \mathrm{U} / \mathrm{L}$ (ref 35-105), gamma-glutamyltransferase $337 \mathrm{U} / \mathrm{L}$ (ref 15-115) and bilirubin $26 \mu \mathrm{mol} / \mathrm{L}(\mathrm{ref}<20)$ (Fig. 1). He had severely reduced partial pressure of oxygen in arterial blood to the inspired oxygen ratio $\left(\mathrm{paO}_{2} / \mathrm{FiO}_{2}\right)$ at $31.3 \mathrm{kPa}$ (ref 55-65) (Fig. 2). Computed tomography (CT) scan revealed ground-glass opacities in both lungs, extensive unspecific changes in the colon, multiple enlarged paraaortic lymph nodes, fat tissue reaction in the posterior abdominal wall (Fig. 3), an enlarged liver at $19 \mathrm{~cm}$ in the
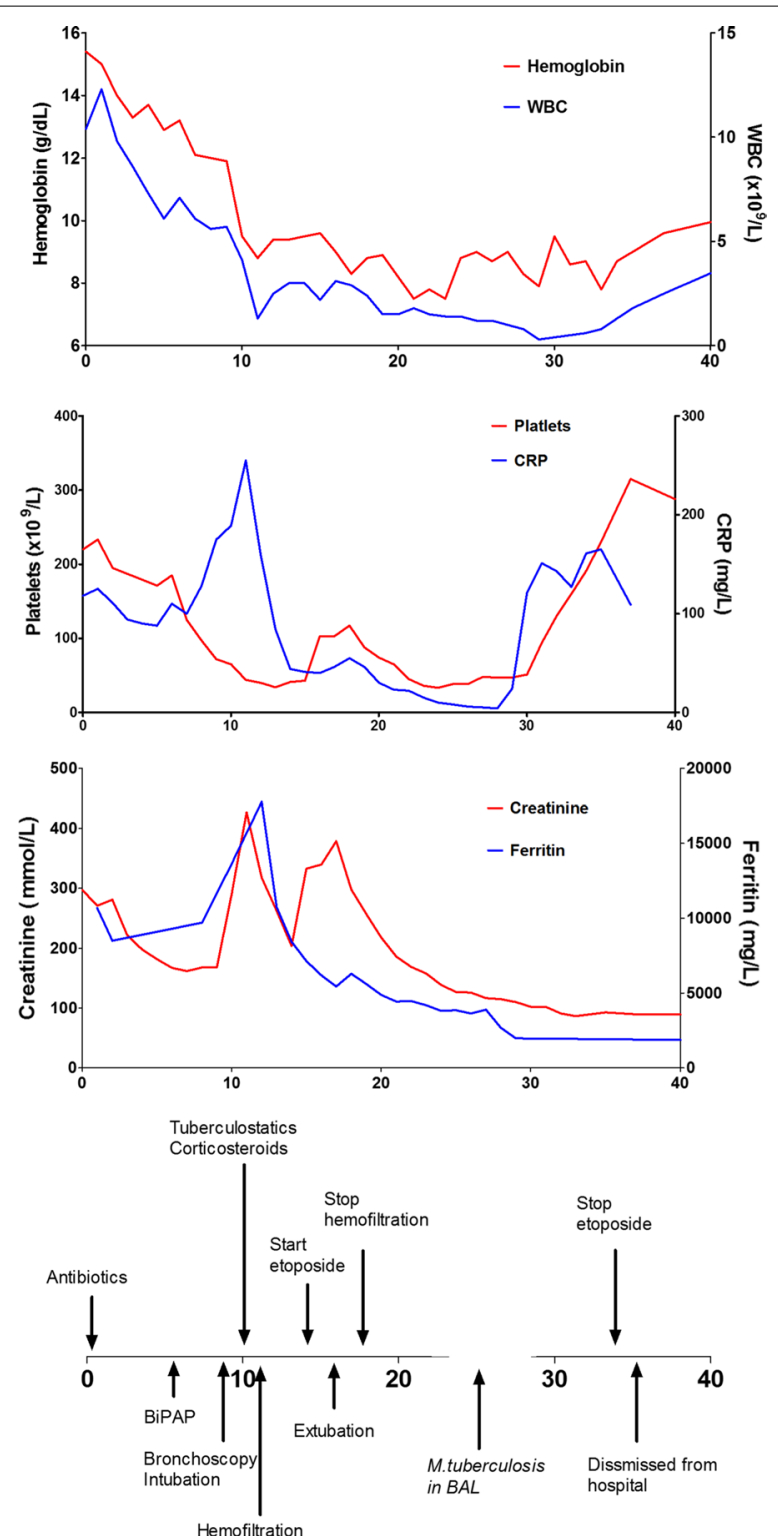

Fig. 1 Development in biochemical parameters during the disease course. Day 0 is the first day of hospitalization, and the timing of various diagnostic and prognostic approaches are marked in the graph

midclavicular line with rounded margins, and a slightly enlarged spleen at $14 \mathrm{~cm}$.

On admission, the clinical presentation was not clearcut, and the attending clinician considered the possibility of viral or bacterial infections, including pneumonia (fever, dyspnea, auscultatory crackles), possibly due to atypical agents, as well as urinary tract infection, hepatitis, intra-abdominal infection, gastroenteritis with ensuing hemolytic uremic syndrome, and a variety of noninfectious diseases including renal failure due to 


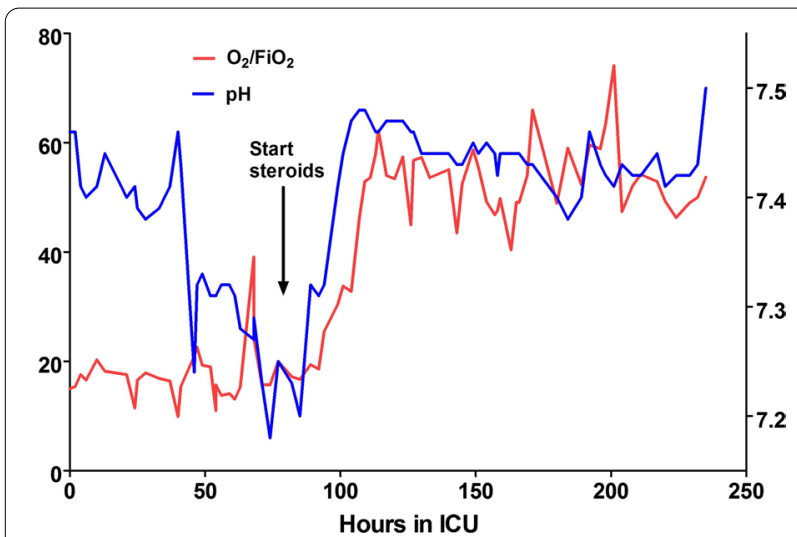

Fig. 2 Oxygenation ( $\mathrm{paO}_{2} / \mathrm{F}_{\mathrm{i}} \mathrm{O}_{2}$ ratio) and ventilation $(\mathrm{pH})$ during the intensive care unit (ICU) stay. Time is marked as hours after ICU attendance. The arrow marks the start time point for steroid treatment

dehydration, vasculitis, other systemic diseases, heart failure and thromboembolism. Broad-spectrum antibiotic (piperacillin-tazobactam) was started to cover for bacterial infection of unknown origin. No clinical improvement was observed the following week, and due to increasing respiratory failure, he was transferred to the nearest regional university hospital for bronchoscopy and further diagnostics. Piperacillin-tazobactam was given from admission and meropenem from day 7 , with the addition of azithromycin from day 9 for a suspected bacterial etiology, but without any clinical or biochemical improvement. He developed increasing respiratory failure that required noninvasive ventilation from day 7 , and progressive hypoxemia necessitated intubation at day 10. Continuous renal replacement therapy was initiated from day 11 due to increasing kidney failure as evidenced by decreasing diuresis, metabolic acidosis and increasing serum creatinine levels (Figs. 1, 2). Despite lung protective ventilatory support, the $\mathrm{paO}_{2} / \mathrm{FiO}_{2}$ rapidly deteriorated (Fig. 2). On day 11 after admission, the attending clinicians started treatment with high dosages of corticosteroids to cover for a possible autoimmune etiology.

At this point, the diagnostic assessment had not revealed the cause of the severe clinical course. Standard workup for infectious diseases with culturing of blood, urine and stools did not reveal the etiology. Serological tests for human immunodeficiency virus (HIV) and hepatitis A and B were all negative. Serology revealed prior but not active infection with Epstein-Barr virus (EBV) and cytomegalovirus (CMV). Since the patient had been back in his homeland 1 year prior to hospitalization, tropical infectious diseases with long incubation time were considered. With fever, pancytopenia and splenomegaly, he displayed the cardinal signs of visceral leishmaniasis, but microscopy of blood and bone marrow aspirate did not reveal visible Leishmania amastigotes, serology was negative and polymerase chain reaction
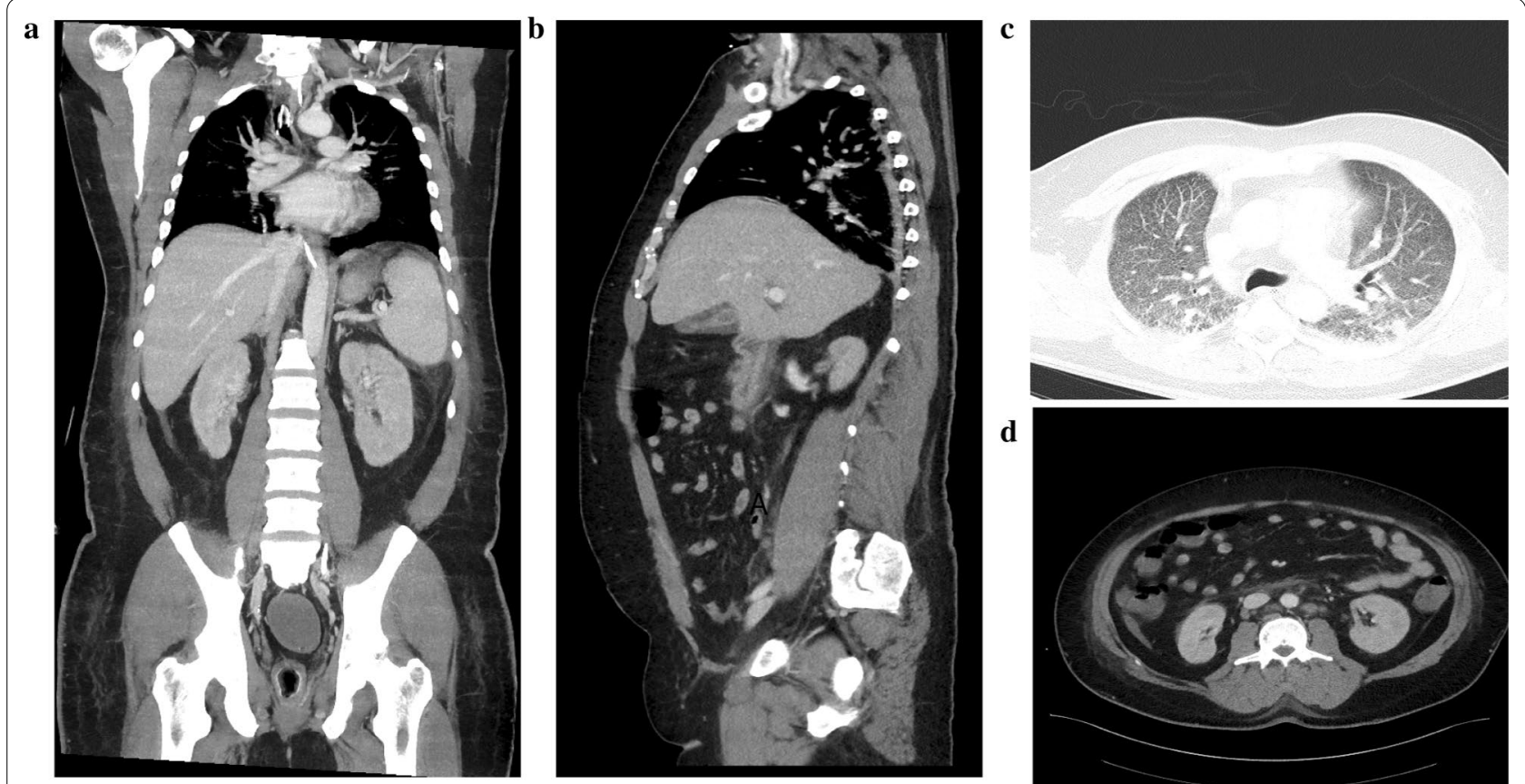

Fig. 3 Radiological examination of the patient. Computed tomography scan images of the abdomen taken at admission demonstrating enlarged spleen and liver, lymphadenopathy in the abdomen, thickened wall of colon and bile duct, and atelectasis in the lung sections 
(PCR) of blood could not detect Leishmania DNA. Serology for strongyloides was also negative. Considering the febrile illness with pulmonary opacities, respiratory failure and subacute deterioration of multiple organ systems, miliary TB was recognized as a possible diagnosis. Interferon gamma release essay (IGRA, QuantiFERON ${ }^{\circledR}$ ) taken at admission was positive at a medium level at $1.98 \mathrm{IU} / \mathrm{mL}$. Upon transfer to the regional hospital, a new IGRA test was taken with negative/inconclusive results, with a value of $0.21 \mathrm{IU} / \mathrm{mL}$, and a repeat test showed a gray zone result of $0.39 \mathrm{IU} / \mathrm{mL}$ (reference values negative $<0.26$, gray zone $0.26-0.43$, low positive $0.44-0.69$, medium positive $0.70-3.99$, strong positive $\geq 4.00$ ). No immunosuppressive treatment had been given at this point. Direct microscopy of bronchial fluid obtained by bronchoscopy did not show acid-fast bacilli, and PCR on the same specimen was negative for Mycobacterium tuberculosis.

However, these findings could not exclude TB infection. Therefore, the patient was given therapy with rifampicin and isoniazid intravenously, and pyrazinamide on nasogastric tube, against possible TB infection at the same time as steroids were started. Intravenous levofloxacin was added to cover for other potential bacterial infections. Although levofloxacin also has antimycobacterial properties, it is not part of standard first-line antiTB treatment.

An exceptionally rapid improvement of the respiratory failure was seen after initiating treatment with high dosage of steroids and tuberculostatic drugs (Fig. 2). The kidney failure continued, however, and the bone marrow failure was worsening, with rapidly decreasing thrombocyte and white blood cell count (WBC) (Fig. 1). Since admission, the patient had persistent fever, increasing levels of serum ferritin to a maximum value of $17,000 \mu \mathrm{g} / \mathrm{L}$ (ref 34-300), splenomegaly and increasing pancytopenia, in addition to hypertriglyceridemia with serum triglycerides of $5.2 \mathrm{mmol} / \mathrm{L}$ (ref $0.45-2.60)$. Based on these clinical and laboratory findings, a diagnosis of HLH was suspected (Table 1). Two weeks after admission, blood tests were analyzed for soluble IL-2 receptor and natural killer (NK)-cell activity, and bone marrow biopsy was performed. An eliciting cause for HLH was sought. Tests for antinuclear antibody (ANA) and antineutrophil cytoplasmic antibody (ANCA) were both negative. Immunophenotyping of bone marrow showed no evidence of lymphoproliferative diseases with $\mathrm{T}$ - or B-cell clonality. Lymphadenopathy of the posterior abdominal wall and wall thickening of the colon seen on CT scan at admission disappeared after initiation of corticosteroid therapy, and biopsy was no longer possible.

At day 10, the patient fulfilled five out of eight diagnostic criteria for HLH (fever, splenomegaly, bi-cytopenia, hypertriglyceridemia and hyperferritinemia), and treatment with etoposide $75 \mathrm{mg} / \mathrm{m}^{2}$ was initiated according to the HLH-2004 protocol [14], although with 50\% dose reduction due to cytopenia and hyperbilirubinemia, and without cyclosporine A (Fig. 1). Over the next days a rapid improvement of the kidney function, decrease in serum ferritin levels and improvement of the general condition were observed (Fig. 1). All anti-TB drugs were discontinued, as all tests for TB apart from the interferongamma release assay remained negative, and TB was considered less likely. Levofloxacin was continued. Three weeks after admission, however, culture of bronchial fluid, stool and urine revealed M. tuberculosis and was also positive on the antigen MPT64 assay, confirming the diagnosis of TB. Results from bone marrow biopsy later revealed an expanded erythropoiesis, increased number of histiocytic cells with phagocytosed lymphocytes and nuclear debris (hemophagocytosis) and granulomas that supported the diagnosis of $\mathrm{HLH}$ and $\mathrm{TB}$, respectively (Fig. 4). The bone marrow was also later found to be positive for M. tuberculosis by PCR. Level of IL-2 receptor was increased to 15,000 U/mL (ref 45-1100), and NK-cell

Table 1 The diagnostic criteria for hemophagocytic lymphohistiocytosis with definitions

\begin{tabular}{|c|c|c|}
\hline Findings & Definitions & Present \\
\hline Fever & Peak temperature of $>38.5^{\circ} \mathrm{C}$ for $>7$ days & $x$ \\
\hline Splenomegaly & Spleen palpable $>3 \mathrm{~cm}$ below costal margin & $X$ \\
\hline Cytopenia & Involving $>2$ cell lines; $\mathrm{Hb}<9.0 \mathrm{~g} / \mathrm{dL}, \mathrm{ANC}<1.0 \times 10^{9} / \mathrm{L}$, platelets $<100 \times 10^{9} / \mathrm{L}$ & $X$ \\
\hline Hypertriglyceridemia or hypofibrinogenemia & $\begin{array}{l}\text { Fasting triglycerides }>2.0 \mathrm{mmol} / \mathrm{L} \text { or }>3 \text { SD more than normal value for age or fibrino- } \\
\text { gen }<1.5 \mathrm{~g} / \mathrm{L} \text { or }>3 \mathrm{SD} \text { less than normal value for age }\end{array}$ & $X$ \\
\hline Hemophagocytosis & Hemophagocytosis demonstrated in biopsy samples of bone marrow, spleen or lymph nodes & $x$ \\
\hline Low or absent NK cell activity & Reduced NK cell activity as measured by standardized assay & \\
\hline Hyperferritinemia & Serum ferritin $>500 \mathrm{ng} / \mathrm{mL}$ & $x$ \\
\hline Elevated soluble interleukin-2 (CD25) levels & CD25 level > $2400 \mathrm{U} / \mathrm{mL}$ & $x$ \\
\hline
\end{tabular}

$\mathrm{Hb}$ hemoglobin, ANC absolute neutrophil count, SD standard deviation, NK natural killer 

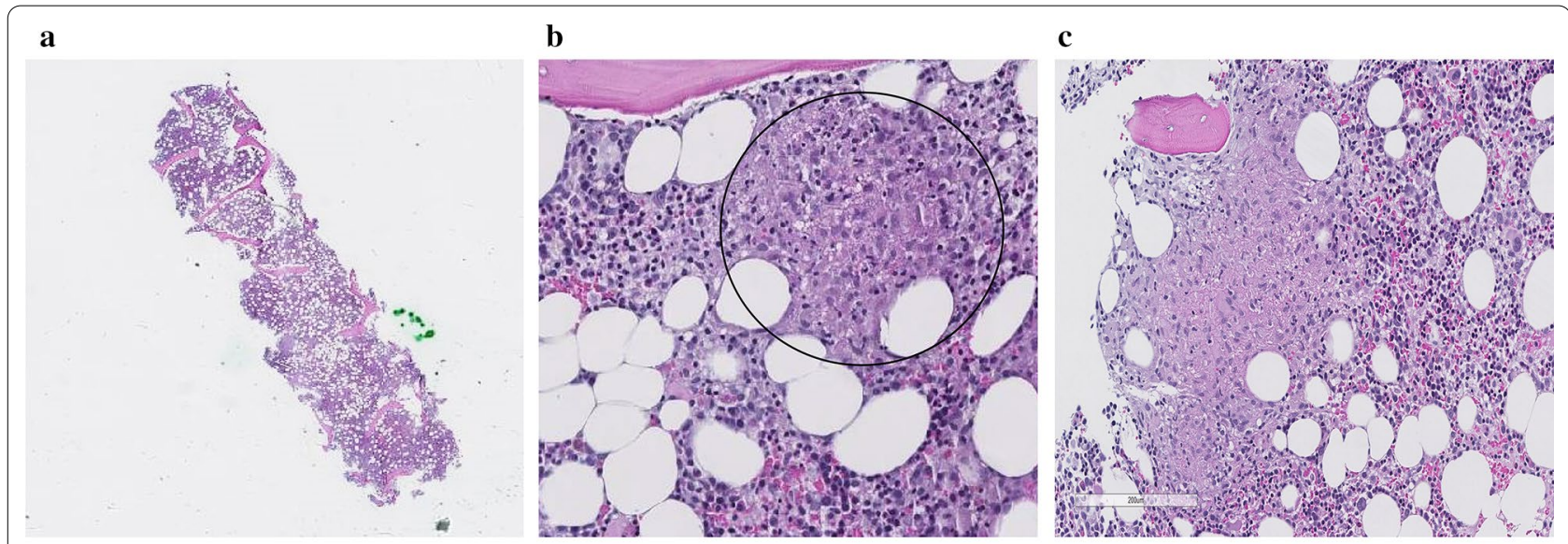

d

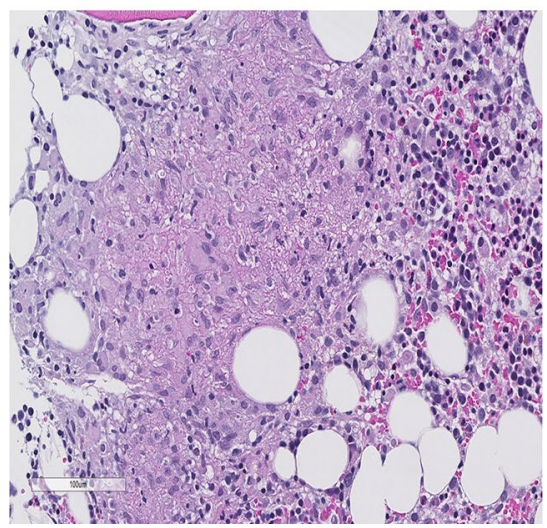

e

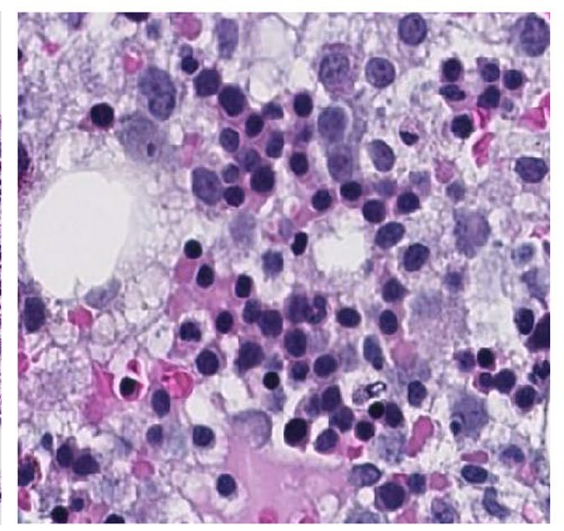

f

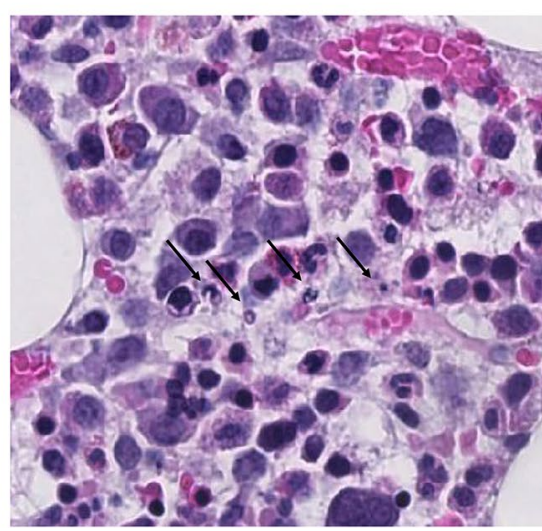

Fig. 4 Histopathological features of the bone marrow. The figure demonstrates bone marrow findings for the patient with hematoxylin and eosin staining. a Overview of the bone marrow demonstrating hypercellular bone marrow with bone marrow cellularity of approximately $70 \%$. b Encircled area displays groups of epithelioid cells consistent with granulomas. c Higher resolution demonstrating epitheliod cell granulomas located within the bone marrow. $\mathbf{d}$ Demonstrating granuloma with several giant cells present. e A significantly expanded erythropoiesis. f Several macrophages with intracytoplasmic residues of nuclear fragments consistent with hemophagocytosis (arrows)

activity was slightly above the normal range at $64 \%$ (ref 18-59).

Taken together, the patient met seven out of eight diagnostic criteria for HLH as stated by the HLH-2004 trial (Table 1) [14]. Miliary TB was regarded as the triggering factor. The TB isolate was likely susceptible to rifampicin and isoniazid, the most important first-line anti-TB drugs, as line-probe assay (GenoType MTBDRplus, Hain Lifescience) showed no mutations conveying resistance to rifampicin or isoniazid in the $\operatorname{rpoB}$, kat $G$ and inh $A$ genes. Thus, the patient received standard anti-TB treatment with rifampicin, isoniazid, pyrazinamide and ethambutol, in the form of four-drug fixed-dose combination tablets (FDCs) [15].

Treatment of secondary HLH is directed against the underlying disease; however, initial treatment with steroids and/or immunosuppressants is usually required to prevent rapidly progressing organ damage and death. Etoposide was discontinued after 3 weeks due to increasing cytopenia, while steroids were continued with tapering doses every 14 days over a 6 -week period (Fig. 1). Towards the end of the hospital stay the patient received 5 days of additional treatment with intravenously administered ceftriaxone, due to a febrile condition probably related to neutropenia (neutrophils at $0.110^{9} / \mathrm{L}$ ). His general clinical condition was rapidly improving, and after 1 month of hospitalization he was discharged with biochemical recovery including decreasing serum ferritin. In light of the severe initial disease, the initial-phase anti-TB-treatment with fourdrug FDCs was extended for a total of 3 months, and the subsequent continuation-phase treatment with two-drug FDCs containing rifampicin and isoniazid was given for 6 months, for a total treatment duration of 9 months. On subsequent outpatient visits, the patient's condition has continuously improved, and he is currently without any sequela or signs of active disease. 


\section{Discussion}

HLH is a life-threatening immune syndrome caused by the massive production of cytokines due to a highly stimulated but ineffective immune response. The pathogenesis of HLH is complicated and not completely understood, but secondary hyperactivation of macrophages and $\mathrm{CD} 8+\mathrm{T}$ lymphocytes in the absence of regulatory NK cell activity seems essential. This results in the massive production of proinflammatory cytokines that directly provokes end organ damage [1-6]. The diagnosis of HLH is challenging and can often be overlooked or delayed. As no single diagnostic test exists, the diagnostic criteria applied in the HLH-2004 trial are currently used to diagnose HLH (Table 1). Hyperferritinemia is often the first clue to the diagnosis. Although the diagnostic criteria consider ferritin $>500 \mu \mathrm{g} / \mathrm{L}$ as diagnostic, the ferritin levels are often considerably more elevated [16], as was the case for our patient presenting with serum ferritin increasing to $>17,000 \mu \mathrm{g} / \mathrm{L}$. If additional cytopenias are present, involving at least two lines, this should clearly raise the clinical suspicion of HLH. Our patient developed thrombocytopenia and anemia, which led to further investigation for suspected HLH. Fasting hypertriglyceridemia and/or hypofibrinogenemia can also quite easily be detected, while assays for soluble IL-2 receptor and NK cell activity are often not readily available in standard hospital laboratories. A biopsy demonstrating hemophagocytosis is of considerable help, as in our patient (Fig. 2). Bone marrow biopsies are easily obtained, and mandatory to rule out secondary causes of HLH such as underlying malignant disorders or visceral leishmaniasis.

The etiology of HLH can be categorized as primary and secondary causes (Table 2). Primary HLH is very rare in adults and is caused by loss of function in genes associated with vesicle trafficking in cytotoxic $\mathrm{T}$ and/ or NK cells [17]. This results in reduction or loss of the cytotoxic potential in NK and T cells, and inability of the immune system to sufficiently eliminate activated macrophages $[18,19]$. Although primary HLH is caused by an underlying genetic immunodeficiency, clinical presentation is usually triggered by a viral infection, most commonly EBV [20]. Secondary HLH can be triggered by both malignant and nonmalignant diseases (Table 2) [21]. Malignant disorders often associated with secondary HLH include hematological malignancies such as lymphoma, acute leukemias and myelodysplastic syndrome, but the syndrome has also been observed in relation to solid tumors [22]. The nonmalignant conditions associated with HLH can be broadly divided into autoimmune disorders and infectious diseases. Among autoimmune disorders we find diseases such as systemic lupus erythematosus (SLE), systemic-onset juvenile idiopathic arthritis (Still's disease) and rheumatoid arthritis. The most common infections reported to be associated with HLH include EBV, leishmaniasis, CMV, HIV and fungal infections [12], and most recently SARS-CoV-2 [23]. The association between TB and HLH has been described previously. However, most of the cases described are in immunocompromised patients, including patients with concomitant malignant disorders, HIV, patients on hemodialysis and renal transplant recipients [11].

Diagnosis of pulmonary TB is rapid and straightforward when acid-fast bacilli can be seen on direct microscopy. However, negative microscopy does not rule out TB. Extrapulmonary TB is particularly challenging to diagnose, as direct microscopy and PCR have low sensitivity on specimens such as pus, cerebrospinal fluid, biopsies and lymph nodes. Although TB bacteria are present throughout the lungs in miliary $\mathrm{TB}$, the majority of these patients have no visible acid-fast bacilli on sputum microscopy. As in our case, definitive diagnosis of microscopy-negative TB relies on a culture for $M$. tuberculosis, which may take up to 6-8 weeks to become

Table 2 Classification of HLH

\begin{tabular}{|c|c|c|c|c|}
\hline \multirow[t]{3}{*}{ Primary HLH } & \multicolumn{4}{|l|}{ Secondary HLH } \\
\hline & \multicolumn{2}{|l|}{ Malignant } & \multicolumn{2}{|l|}{ Nonmalignant } \\
\hline & Hematological malignancies & Solid tumors & Autoimmune & Infectious \\
\hline Genetic defects impairing NK and T cell function & $\begin{array}{l}\text { Lymphoma } \\
\text { Acute leukemias } \\
\text { MDS }\end{array}$ & $\begin{array}{l}\text { Lung } \\
\text { Gl tract } \\
\text { Pancreas } \\
\text { UG tract }\end{array}$ & $\begin{array}{l}\text { SLE } \\
\text { Still's disease } \\
\text { Rheumatoid arthritis }\end{array}$ & $\begin{array}{l}\text { EBV } \\
\text { Leishmania } \\
\text { CMV } \\
\text { SARS-CoV-2 } \\
\text { HIV } \\
\text { Protozoa } \\
\text { Fungal infections } \\
\text { TB }\end{array}$ \\
\hline
\end{tabular}


positive. While PCR has high specificity and can rapidly identify $M$. tuberculosis, its sensitivity is far inferior to culture.

The classical description of miliary TB is that of hematogenous seeding occurring successively after primary infection and resulting in millet-like grains in various organs, including the lungs, where these grains result in typical findings on chest X-ray. Pathological examination typically shows granulomas, as was found on the bone marrow specimen from our patient, and is highly suggestive of the diagnosis. The term cryptic miliary TB is sometimes used to describe similar seeding occurring later in conjunction with reactivated TB ("post-primary" TB), and tending to affect older individuals, often without typical X-ray findings. A third form, nonreactive TB, describes widespread seeding of TB where there is dysfunctional immune response, allowing the bacteria to spread without formation of granulomas, and frequently without "miliary" characteristics on chest X-ray. Nonreactive TB often occurs in immunocompromised patients, including HIV patients with low CD4 (cluster of differentiation 4) counts. The term disseminated TB is often used interchangeably with miliary $\mathrm{TB}$, but sometimes reserved for nonreactive $\mathrm{TB}$ or widespread $\mathrm{TB}$ without typical miliary findings on chest X-ray. The patient's origin in a TB-endemic region suggested that he suffered from cryptic miliary TB due to reactivation many years after primary infection. Nonreactive TB was unlikely, as he had granuloma formation on pathological examination, and no underlying immunosuppression could be found. The National Reference Laboratory for Mycobacteria (NRL) at the Norwegian Institute of Public Health performed phenotypical drug susceptibility testing using the BACTEC MGIT 960 system (Becton Dickinson, NJ, USA), confirming susceptibility to all primary anti-TB drugs, as well as relatedness analysis with comparison to isolates from patients diagnosed with TB in Norway during the last 8 years. Interestingly, MIRU-VNTR (mycobacterial interspersed repetitive unit-variable number tandem repeat) typing first suggested that the isolate could be related to one obtained from a patient diagnosed with $\mathrm{TB}$ in Norway 3 years earlier, consistent with relatively recent primary infection causing classic miliary TB. However, whole-genome sequencing (on an Illumina platform) excluded relatedness to this isolate (in-house methodology), supporting the initial theory of cryptic miliary TB caused by reactivation decades after primary infection.

Diagnostics of TB-triggered HLH is particularly challenging, as HLH and miliary TB have several features in common, particularly fever, splenomegaly and anemia, but also lymphopenia, thrombocytopenia and elevated ferritin. While anemia is seen in most miliary TB patients, only up to one quarter have lymphopenia or thrombocytopenia as well [24]. Thrombocytopenia in TB can result from immune-mediated destruction, hypersplenism and infiltration of the bone marrow [25]. While ferritin is usually moderately increased in TB, values in excess of $10,000 \mathrm{ng} / \mathrm{mL}$ have been described in miliary TB [24]. Our patient's symptoms and findings coincided with the multiple sites from which $M$. tuberculosis was recovered, but could also represent organ damage due to HLH. Hence pollakiuria and renal failure could be due to affection of kidneys and the urinary tract, history of diarrhea, colonic changes and abdominal fat tissue reaction on CT due to affection of the intestines, and notably, dyspnea, pulmonary crepitation, respiratory failure and ground-glass opacities on CT due to affection of the lungs. The bone marrow biopsy confirmed evidence of both hemophagocytosis and TB. The pathophysiology of HLH related to TB is mainly unknown. Phagocytosis of M. tuberculosis by macrophages, and hence Th1-mediated cytotoxicity, followed by release of a large quantity of cytokines and chemokines are probably involved [11]. HLH due to TB has a high mortality rate, and most reports describe fatal outcome, particularly if other complicating factors are present [11, 26, 27]. The treatment of HLH is challenging, and simultaneous immunosuppressive treatment for HLH combined with specific treatment of the underlying condition is necessary [16]. Given the rarity of the disease, few studies describing treatment alternatives exist. In most treatment regimens, etoposide is combined with corticosteroids [16, 28, 29].

The greatest obstacle to a successful outcome for individuals with HLH is a delayed diagnosis. As soon as the diagnosis is suspected or confirmed, treatment should be initiated. The major aims for HLH therapy are to suppress the life-threatening inflammation and to treat the underlying cause. Therapy based on the HLH-94 and HLH-2004 protocols consists of a series of weekly treatments with corticosteroids and etoposide, with the addition of intrathecal methotrexate and hydrocortisone for those with central nervous system (CNS) involvement $(14,30)$. For patients with an underlying infection, treatment of the triggering condition should be initiated simultaneously, as treatment of the trigger has the potential to remove the stimulus for immune activation. For the current case, the underlying condition, TB, was treated with rifampicin, isoniazid, pyrazinamide and ethambutol. However, in the case of TB-triggered HLH, it is particularly challenging that the immunosuppressive treatment indicated for HLH can severely exacerbate the course of TB. In the absence of tuberculostatic drugs, the treatment for HLH would have impaired the patient's immunity to an extent that could result in fulminant, disseminated TB. Beyond this rare situation of HLH, miliary $\mathrm{TB}$ should always be considered before instituting 
immunosuppressive treatment for febrile illnesses of suspected immunological genesis. While treatment for TB was critical for the survival of the patient, therapy against HLH seemed appropriate as well, and in accordance with generally accepted treatment algorithms. This is supported by the fact that our patient had an improvement of his respiratory failure after treatment with steroids and anti-TB drugs was initiated, but only had improvement in his kidney and bone marrow failure after etoposide was added.

To conclude, TB-associated HLH is an exceedingly rare condition, but should be considered for patients with risk factors for TB presenting with severe signs of organ failure, and clinical or laboratory findings consistent with HLH. The incidence of TB is declining globally, but it is still highly endemic in some countries. Awareness of $\mathrm{HLH}$ as a complication of TB and other chronic infectious diseases such as HIV, leishmaniasis and hepatitis is important for early diagnosis and adequate management.

\begin{abstract}
Abbreviations
ANA: Antinuclear antibody; ANCA: Antineutrophil cytoplasmic antibody; CMV: Cytomegalovirus; CRP: C-reactive protein; CT: Computed tomography; EBV: Epstein-Barr virus; HIV: Human immunodeficiency virus; HLH: Hemophagocytic lymphohistiocytosis; PCR: Polymerase chain reaction; TB: Tuberculosis; WBC: White blood cell count.
\end{abstract}

\section{Acknowledgements}

We thank Paul Christoffer Lindemann and the Department of Microbiology and Immunology, Haukeland University Hospital, for permission to use the results of microbiological analyses. We are grateful to Anne Torunn Mengshoel, National Reference Laboratory for Mycobacteria, Norwegian Institute of Public Health, for assistance with analysis and interpretation of data from phylogenetic studies and drug susceptibility testing. All health care workers involved in the treatment of the patient are acknowledged.

\section{Authors' contributions}

LT initiated the work, treated the patient, and wrote and edited the manuscript; MS wrote the manuscript and was responsible for the layout; BB initiated the work, treated the patient and wrote the manuscript; $\mathrm{GH}$ treated the patient and contributed with scientific considerations; ABB treated the patient and contributed with scientific considerations; THAT treated the patient and contributed with scientific considerations; OV was responsible for pathological diagnostics and contributed with scientific considerations; HR initiated and coordinated the work, created the figures, and wrote and edited the manuscript. All authors read and approved the final manuscript.

\section{Funding}

None.

\section{Availability of data and materials \\ Not applicable.}

Ethics approval and consent to participate

Written consent was obtained from the patient.

\section{Consent for publication}

Written informed consent was obtained from the patient for publication of this case report and any accompanying images. A copy of the written consent is available for review by the Editor-in-Chief of this journal.

\section{Competing interests}

The authors declare that they have no competing interests.

\section{Author details}

1 Department of Medicine, Haukeland University Hospital, Bergen, Norway. ${ }^{2}$ Department of Clinical Science, Institute of Clinical Science, University of Bergen, Bergen, Norway. ${ }^{3}$ Department of Surgical Services, Haukeland University Hospital, Bergen, Norway. ${ }^{4}$ Department of Pathology, Haukeland University Hospital, Bergen, Norway. ${ }^{5}$ Departemnt of Medical Science, University of Bergen, Bergen, Norway.

Received: 7 July 2020 Accepted: 11 October 2020

Published online: 11 November 2020

\section{References}

1. Allen CE, McClain KL. Pathophysiology and epidemiology of hemophagocytic lymphohistiocytosis. Hematol Am Soc Hematol Educ Program. 2015;2015:177-82.

2. Schram AM, Berliner N. How I treat hemophagocytic lymphohistiocytosis in the adult patient. Blood. 2015;125(19):2908-14.

3. Janka GE, Lehmberg K. Hemophagocytic syndromes_-an update. Blood Rev. 2014;28(4):135-42.

4. Marsh RA, Haddad E. How I treat primary haemophagocytic lymphohistiocytosis. Br J Haematol. 2018;182(2):185-99.

5. Lehmberg K, Ehl S. Diagnostic evaluation of patients with suspected haemophagocytic lymphohistiocytosis. Br J Haematol. 2013;160(3):275-87.

6. Zhang K, Jordan MB, Marsh RA, Johnson JA, Kissell D, et al. Hypomorphic mutations in PRF1, MUNC13-4, and STXBP2 are associated with adultonset familial HLH. Blood. 2011;118(22):5794-8.

7. Risma KA, Marsh RA. Hemophagocytic lymphohistiocytosis: clinical presentations and diagnosis. J Allergy Clin Immunol Pract. 2019;7(3):824-32.

8. Riviere S, Galicier L, Coppo P, Marzac C, Aumont C, et al. Reactive hemophagocytic syndrome in adults: a retrospective analysis of 162 patients. Am J Med. 2014;127(11):1118-25.

9. MacNeil A, Glaziou P, Sismanidis C, Maloney S, Floyd K. Global epidemiology of tuberculosis and progress toward achieving global targets—2017. MMWR Morb Mortal Wkly Rep. 2019;68(11):263-6.

10. Global tuberculosis report 2019. Geneva: World Health Organization; 2019. Licence: CC BY-NC-SA 3.0 IGO.

11. Brastianos PK, Swanson JW, Torbenson M, Sperati J, Karakousis PC Tuberculosis-associated haemophagocytic syndrome. Lancet Infect Dis. 2006;6(7):447-54.

12. Tseng YT, Sheng WH, Lin BH, Lin CW, Wang JT, et al. Causes, clinical symptoms, and outcomes of infectious diseases associated with hemophagocytic lymphohistiocytosis in Taiwanese adults. J Microbiol Immunol Infect. 2011;44(3):191-7.

13. Riccardi N, Pontarelli A, Alagna R, Saderi L, Ferrarese M, et al. Epidemiology and treatment outcome of MDR and pre-XDR TB in international migrants at two reference centers in the North of Italy: a cross-sectional study coordinated by Stop TB Italia Onlus. Public Health. 2020;180:17-21.

14. Henter Jl, Horne A, Arico M, Egeler RM, Filipovich AH, et al. HLH-2004: Diagnostic and therapeutic guidelines for hemophagocytic lymphohistiocytosis. Pediatr Blood Cancer. 2007;48(2):124-31.

15. Blomberg B, Spinaci S, Fourie B, Laing R. The rationale for recommending fixed-dose combination tablets for treatment of tuberculosis. Bull World Health Organ. 2001;79(1):61-8.

16. La Rosee P, Horne A, Hines M, von Bahr GT, Machowicz R, et al. Recommendations for the management of hemophagocytic lymphohistiocytosis in adults. Blood. 2019;133(23):2465-77.

17. Stepp SE, Dufourcq-Lagelouse R, Le Deist F, Bhawan S, Certain S, et al. Perforin gene defects in familial hemophagocytic lymphohistiocytosis. Science. 1999;286(5446):1957-9.

18. Jenkins MR, Rudd-Schmidt JA, Lopez JA, Ramsbottom KM, Mannering SI, et al. Failed CTL/NK cell killing and cytokine hypersecretion are directly linked through prolonged synapse time. J Exp Med. 2015;212(3):307-17.

19. Janka GE, Lehmberg K. Hemophagocytic lymphohistiocytosis: pathogenesis and treatment. Hematol Am Soc Hematol Educ Program. 2013;2013:605-11.

20. Filipovich A, McClain K, Grom A. Histiocytic disorders: recent insights into pathophysiology and practical guidelines. Biol Blood Marrow Transplant. 2010;16(1 Suppl):S82-9. 
21. Yoon JH, Park SS, Jeon YW, Lee SE, Cho BS, et al. Treatment outcomes and prognostic factors in adult patients with secondary hemophagocytic lymphohistiocytosis not associated with malignancy. Haematologica. 2019;104(2):269-76.

22. Daver N, McClain K, Allen CE, Parikh SA, Otrock Z, et al. A consensus review on malignancy-associated hemophagocytic lymphohistiocytosis in adults. Cancer. 2017;123(17):3229-40.

23. Mehta P, McAuley DF, Brown M, Sanchez E, Tattersall RS, et al. COVID-19: consider cytokine storm syndromes and immunosuppression. Lancet. 2020;395(10229):1033-4.

24. Arranz Caso JA, Garcia Tena J, Llorens MM, Moreno R. High serum ferritin concentration in an AIDS patient with miliary tuberculosis. Clin Infect Dis. 1997;25(5):1263-4.

25. Weber SF, Belard S, Rai S, Reddy R, Belurkar S, et al. Immune thrombocytopenia secondary to tuberculosis: a case and review of literature. Int J Tuberc Lung Dis. 2017;21(4):466-70.

26. Zhang Y, Liang G, Qin H, Li Y, Zeng X. Tuberculosis-associated hemophagocytic lymphohistiocytosis with initial presentation of fever of unknown origin in a general hospital: an analysis of 8 clinical cases. Medicine (Baltimore). 2017;96(16):e6575
27. Kessler M, Reinig E. HLH associated with disseminated tuberculosis. N Engl J Med. 2020;382(18):1749.

28. Bergsten E, Horne A, Arico M, Astigarraga I, Egeler RM, et al. Confirmed efficacy of etoposide and dexamethasone in HLH treatment: long-term results of the cooperative HLH-2004 study. Blood. 2017;130(25):2728-38.

29. Johnson TS, Terrell CE, Millen SH, Katz JD, Hildeman DA, et al. Etoposide selectively ablates activated $T$ cells to control the immunoregulatory disorder hemophagocytic lymphohistiocytosis. J Immunol. 2014;192(1):84-91.

30. Trottestam H, Horne A, Arico M, Egeler RM, Filipovich AH, et al. Chemoimmunotherapy for hemophagocytic lymphohistiocytosis: long-term results of the HLH-94 treatment protocol. Blood. 2011;118(17):4577-84.

\section{Publisher's Note}

Springer Nature remains neutral with regard to jurisdictional claims in published maps and institutional affiliations.
Ready to submit your research? Choose BMC and benefit from:

- fast, convenient online submission

- thorough peer review by experienced researchers in your field

- rapid publication on acceptance

- support for research data, including large and complex data types

- gold Open Access which fosters wider collaboration and increased citations

- maximum visibility for your research: over $100 \mathrm{M}$ website views per year

At BMC, research is always in progress.

Learn more biomedcentral.com/submissions 